\title{
Volunteers as Active Shapers of their Work: The Role of Job Crafting in Volunteer Satisfaction and Organizational Identification
}

Author Details

\author{
Marlene Walk, PhD \\ Assistant Professor \\ Paul H. O’Neill School of Public and Environmental Affairs \\ 801 W Michigan Street, \\ Indianapolis, IN-46202 \\ IUPUI \\ E-Mail: mwalk@iupui.edu \\ Phone: 317-274 3098 \\ ORCID ID: https://orcid.org/0000-0002-1396-9481 \\ Emily Peterson, MPA \\ Paul H. O'Neill School of Public and Environmental Affairs \\ 801 W Michigan Street, \\ Indianapolis, IN-46202 \\ IUPUI
}

Note: This is the accepted version of the manuscript prior to copy-editing and typesetting.

Please cite as: Walk, M. \& Petersson, E. (forthcoming) Volunteers as active Shapers of their Work: The Role of Job Crafting in Volunteer Satisfaction and Organizational Identification,

VOLUNTAS

Acknowledgements: The first author would like to thank the IUPUI Office of the Vice Chancellor for Research, the IUPUI Office for Women, Indiana University's Public Policy Institute, and Indiana University's Lilly Family School of Philanthropy for their generous support. A version of this paper was presented at the 2021 Academy of Management Meeting. 
We thank participants of the panel Volunteering and Philanthropy (session 151) for their valuable suggestions.

Declarations: Compliance with Ethical Standards: IRB approval was sought and classified as exempt from Indiana University's IRB.

Funding: Partial financial support was received from the IUPUI Office of the Vice Chancellor for Research, the IUPUI Office for Women, Indiana University's Public Policy Institute, and Indiana University’s Lilly Family School of Philanthropy.

Conflicts of interest: The authors declare they have no relevant financial or non-financial interests to disclosed. 


\title{
Volunteers as Active Shapers of their Work: \\ The Role of Job Crafting in Volunteer Satisfaction and Organizational \\ Identification
}

\begin{abstract}
Volunteer satisfaction is a significant concern, as volunteers have lower barriers to exit than employees and tend to leave nonprofits when dissatisfied. While volunteer management predominantly focuses on the implementation of management practices, this study alters that perspective. Through job crafting, one form of proactive behavior in organizational contexts, we study volunteers as active participants in their volunteer experience. We posit that volunteer job crafting is an important, yet overlooked, factor in volunteer outcomes such as satisfaction and organizational identification. We test and (partially) confirm our hypotheses using a sample of 678 volunteers in one youth-serving nonprofit organization in the Midwest region of the United States. This study extends job crafting research further into the non-work domain by adding a multifaceted conceptualization of job crafting in the context of volunteer work. We distinguish between behavioral and cognitive crafting and provide empirical support on how those crafting forms relate to volunteer satisfaction and organizational identification.
\end{abstract}

Keywords: job crafting, behavioral crafting, cognitive crafting, organizational identification, satisfaction, volunteers 


\section{Introduction}

Most nonprofits rely on volunteer labor for the provision of their services (Hager \& Brudney, 2008). Volunteers are included in all aspects of service delivery and program administration ranging from administrative tasks to leadership roles (Willems \& Walk, 2013). Volunteers, however, differ from paid employees in what motivates them (Studer \& von Schnurbein, 2013). For instance, volunteers are not bound by a paycheck; consequently, they have lower barriers for exit. Indeed volunteers have been found to leave nonprofits, when they are dissatisfied rather than continue to give their time (Haivas et al., 2013).

Research has explored the effectiveness and impact of volunteer management practices on outcomes such as satisfaction, intent to stay, and turnover (Einolf, 2018; Henderson \& Sowa, 2018; Walk et al., 2019). Whereas this perspective is important and provides those managing volunteers with valuable strategies, it de-emphasizes the volunteer experience, an area of inquiry where more research is needed (Wilson, 2012). To better capture the volunteer experience, scholars have started to explore how volunteers perceive and engage in their volunteer environments through engagement (Erks et al., 2020; Traeger \& Alfes, 2019), organizational citizenship behavior (Erks et al., 2020), and volunteer proactivity (do Nascimento et al., 2018). The present study aligns with this volunteer-centered perspective by focusing on the role of job crafting.

Job crafting, a type of proactive behavior in organizational contexts, captures the physical and cognitive changes individuals make in their work (Wrzesniewski \& Dutton, 2001). Job crafting is becoming increasingly important given the changing nature of work; Dutton and Wrzesniewski (2020) posit "the principles of job crafting remain deeply relevant in a world where job structure is rapidly changing, putting more and more responsibility on the individual 
for the experience and engagement in their work". This notion applies well to the nonprofit context where organizational changes, especially following external events such as new policies and legislation, are becoming the norm resulting in internal restructuring and requiring employees and volunteers to adapt to new situations (Akingbola et al., 2019).

This article spotlights volunteer proactivity in the form of job crafting. We assume volunteers themselves can impact volunteer outcomes such as satisfaction or organizational identification through job crafting. This assumption is based on an understanding that volunteers are not just passive recipients of management practices but actively engaged in their volunteer work and interested in shaping their volunteer experience (do Nascimento et al., 2018). The research on proactive behaviors has focused almost exclusively on paid employees but understanding proactive work behaviors is critical in the volunteer context (do Nascimento et al., 2018). To date, we do not know much about volunteers' proactive behaviors in general or job crafting specifically. As such, this study poses the following research questions: Who is most likely to proactively craft jobs in the volunteer setting? What are the outcomes of job crafting? What is the relationship between different job crafting forms and those outcomes?

This study makes three contributions. First, this article contributes to theory as it extends the study of proactive behavior in the form of job crafting to the volunteer context (De Bloom et al., 2020). We argue that volunteers engage in job crafting to align their volunteer environment with their needs. Engaging in job crafting, then, serves as a mechanism to increase volunteer satisfaction and organizational identification. A second contribution consists of the conceptualization and operationalization of job crafting as a multifaceted construct in the volunteer context. Whereas the job crafting literature has proposed and tested various multidimensional conceptualizations in the work context, job crafting research in the non-work 
context has only been conceptualized as a single-dimension construct (De Bloom et al., 2020). This limits our understanding of job crafting in the non-work context. Therefore, this study adopts a multifaceted conceptualization of job crafting consisting of behavioral and cognitive job crafting and tests those in the volunteer context. A more general third contribution of our work is the emphasis on the role of volunteers as active shapers of their work through the lens of job crafting as a self-initiated, bottom-up approach towards job design. This notion adds to the emerging research on the volunteer experience as an important factor in volunteer management research (do Nascimento et al., 2018; Erks et al., 2020; Traeger \& Alfes, 2019). Related, and a notable practical implication, is the description of which volunteers are most likely to job craft. Having a better knowledge of who is likely to job craft will enable volunteer managers to design volunteer programs to facilitate bottom-up proactive behavior and to target those opportunities to those likely to be interested in job crafting.

\section{Literature Review and Hypotheses Development}

\section{Job Crafting as Proactive Behavior}

Job crafting is defined as the physical and cognitive changes individuals make in the task, relational, or cognitive boundaries of their work (Wrzesniewski \& Dutton, 2001). Job crafting is one type of proactive behavior individuals can engage in to "impact themselves and/or their environments" (Grant \& Ashford, 2008, p. 4). Generally, proactive behaviors encompass futureoriented actions. Those who engage in proactive behavior aim for change; "they are focused on the goal of meaningfully altering the self, others, or the contexts in which they are situated" (Grant \& Ashford, 2008, p. 9).

Job crafting can take on a variety of forms from choosing to take on additional projects outside of formal responsibilities, collaborating on a social media campaign to viewing customer 
service responsibilities as an opportunity to receive feedback in real-time (Zhang \& Parker, 2019). The goal of job crafting is to make work more meaningful or to avoid aspects individuals do not find value in (Wrzesniewski \& Dutton, 2001). For instance, individuals may job craft to increase their meaning of work (Bruning \& Campion, 2018), psychological well-being (Berg et al., 2010b), and performance and job satisfaction (Bruning \& Campion, 2018; Leana et al., 2009). Whereas job crafting helps the individual, it may not necessarily be beneficial for the

organization (Berg et al., 2013; Dierdorff \& Jensen, 2018). For example, employees who craft to spend more time focusing on the aspects of the job they find meaningful may neglect the core functions of their work, resulting in a loss to the organization.

\section{Job Crafting in the Volunteer Context}

Job crafting has originated from the job design literature. Whereas traditionally, job design is a top-down process encompassing how workplace practices may be improved for individuals, leading to greater productivity and better workplace experiences (Hackman \& Oldham, 1976), job crafting allows individuals to make changes to their work roles 'bottom-up' (Wrzesniewski et al., 2013; Wrzesniewski \& Dutton, 2001). This notion of self-initiated, bottomup job design may be particularly salient in the volunteer context as volunteer jobs tend to be less rigorously designed. For instance, Hager \& Brudney (2008) find that only $44 \%$ of surveyed nonprofits use written policies and job descriptions for their volunteers to a large degree. Further, volunteer work is also characterized by autonomy and flexibility in how volunteer tasks can be completed (Englert et al., 2020); both autonomy and flexibility are influencing factors for job crafting (Wrzesniewski \& Dutton, 2001). We, therefore, deem the job crafting construct as particularly meaningful to study in the volunteer context. 
Indeed, job crafting, although predominantly studied in the work context, applies to nonwork settings as well. De Bloom and colleagues (2020) find "individuals may craft to enhance their sense of belonging as an employee, parent, spouse, or volunteer" (p. 1428). Crafting research outside the work context focuses on leisure crafting — crafting focused on seeking fulfillment in leisure activities to address passions and values (Berg et al., 2010a)—and the boundaries and spillover between work and non-work domains. For instance, Berg and colleagues (2010a) examine how individuals pursue unanswered callings at work through leisure crafting. Similarly, Sturges (2008) investigates how young professionals engage in various crafting activities to increase their work-life balance. Research on leisure crafting or crafting along the boundaries of work and non-work, however, tends to be unidimensional, frequently ignores cognitive crafting strategies, and "has generally disregarded a variety of nonwork roles as domains amenable to crafting" (De Bloom et al., 2020, p. 1426), such as volunteering. The present study aims to fill these gaps in the literature.

Whereas "no distinction has been made in nonwork crafting research between $[\ldots]$ different types of crafting" (De Bloom et al., p. 1438), job crafting in the work context has been treated as a multifaceted construct to understand the nuances of job crafting. The present study distinguishes two job crafting forms - cognitive and behavioral crafting (Zhang \& Parker, 2019), a distinction that closely follows the early conceptualization of job crafting into relational, task (also known as behavioral), and cognitive crafting ${ }^{1}$. In short, behavioral crafting entails doing

\footnotetext{
${ }^{1}$ Since our focus is on cognitive crafting as this crafting form has not received much research attention in the nonwork context (De Bloom et al., 2020), we do not focus on or discuss the job crafting conceptualization based on job demands-resources theory (Tims et al., 2012) as this research stream specifically excludes cognitive crafting (Melo et al., 2021).
} 
more or fewer job-related aspects or doing them differently, while cognitive crafting means reframing a job (Melo et al., 2021). We elaborate on both crafting forms below.

\section{Behavioral Crafting}

Behavioral crafting encompasses physical modifications or the expansion and contraction of a job's task boundaries (Wrzesniewski \& Dutton, 2001; Zhang \& Parker, 2019), such as "altering the form or number of activities one engages in while doing the job" (Wrzesniewski \& Dutton, 2001, p. 179). One example of behavioral crafting may be the incorporation of a new form of technology into the data entry process to increase the efficiency of this routine task (Bruning \& Campion, 2018). Through taking on additional tasks, changing how tasks are performed, or reducing the scope of tasks, behavioral crafting has an immediate and noticeable impact on the function of a job. Research on behavioral crafting specifically indicates that employees who engage in behavioral crafting show higher levels of creativity and organizational citizenship behavior (Lin et al., 2017).

\section{Cognitive Crafting}

Cognitive crafting is centered around internal changes to an individual's attitude and adapting boundaries to better suit individual needs (Wrzesniewski \& Dutton, 2001). Zhang and Parker (2019) suggest "cognitive crafting involves altering how one frames or views their tasks or job, which is self-initiated, self-targeted, intentional, and represents meaningful changes to the job aspects" (p. 130). Cognitive crafting often involves reframing and sensemaking (Melo et al., 2021). A prominent example of this form of crafting involves janitorial staff in a healthcare space reframing their work to perceive it as integral to the overall recovery of the patients (Wrzesniewski \& Dutton, 2001). 
Compared to behavioral crafting, cognitive crafting is intangible (Zhang \& Parker, 2019). Individuals, rather than making changes to the work itself, change how they think about their work as well as their attitudes towards and perceptions of their work (Geldenhuys et al., 2020). Much less is known about cognitive crafting compared to behavioral crafting, given its intangible nature. Still, cognitive crafting may be easier or more intuitive for some individuals as it does not entail engaging in tasks or other behaviors (Zhang \& Parker, 2019). Research on cognitive crafting specifically indicates that employees who engage in cognitive crafting display lower turnover intentions, lower negative affect, and increased task mastery (Hommelhoff et al., 2021).

\section{The Relationship between Behavioral and Cognitive Crafting}

How behavioral and cognitive crafting are related is not fully clear. Most of the research has conceptualized them as distinct but related dimensions of job crafting (Bindl et al, 2019; Kim et al., 2018; Niessen et al., 2016; Slemp \& Vella-Brodrick, 2013; Wrzesniewski \& Dutton, 2001) that "tend to occur together" (Hu et al., 2020, p. 790). Among other things, this is indicated by medium to high correlations between behavioral and cognitive crafting, while the respective fit statistics point to sufficient discriminant validity (e.g., Geldenhuys et al., 2020; Niessen et al., 2016; Weseler et al., 2016). More recent research has started to investigate the temporal dimension between behavioral and cognitive crafting. Some findings indicate that cognitive crafting may precede behavioral crafting (Melo et al., 2021) while others posit behavioral crafting precedes cognitive crafting (Romeo et al., 2020). In this study, we follow the more established research and treat behavioral and cognitive crafting as two related, but distinct forms of job crafting.

Findings from this line of work suggest that the relationship between behavioral crafting, cognitive crafting, and outcomes is complex. For instance, behavioral and cognitive crafting tend 
to be related in the same ways to certain outcomes, but not others. For instance, behavioral and cognitive crafting are both positively related to meaningfulness and in-role performance, while only cognitive crafting is related to extra-role performance (Geldenhuys et al., 2020). Further, Niessen and colleagues (2016) indicated that only cognitive, but not behavioral crafting is related to fit perceptions. Weseler and colleagues (2016) found that behavioral crafting is related to both supervisor-rated and self-rated performance, but cognitive crafting is not.

\section{Job Crafting and Organizational Identification}

The relationship between job crafting and identity has been discussed since the inception of job crafting. In their seminal article, Wrzesniewski and Dutton (2001) indicate "in job crafting theory there is an emphasis on the proactive changes employees make in the boundaries of their work to alter their identity or the meaning of the work" (p. 188). Organizational identity research and theory are grounded in the assumption individuals strive towards positive identities (Gecas, 1982). Wrziesniewski and colleagues (2013) propose "job crafting is an important process through which individuals construct different kinds of positive organizational identities by altering the task, relational, and cognitive boundaries of their work" (p. 292). For instance, Fuller and Unwin (2017) find hospital porters, employed to move patients or goods within a hospital, engaged in job crafting to reframe their occupational identities aiming to expand prescribed boundaries of their work. Still, empirical research on the link between job crafting and organizational identity is scarce and, thus, Wrziesniewski and colleagues (2013) encourage researchers to investigate "which particular forms of job crafting are likely to bring about [...] different meanings and identities" (p. 295).

In this article, we focus on organizational identification as an outcome of job crafting. Pratt (1998) describes organizational identification as a process, which "occurs when an 
individual's beliefs about his or her organization become self-referential or self-defining" ( $\mathrm{p}$. 172). Similarly, Mael and Ashforth (1992) define organizational identification as "the perception of oneness with or belongingness to an organization, where the individual defines him or herself in terms of the organization(s) in which he or she is a member" (p. 104). Building on social identity theory (Tajfel \& Turner, 1979), Mael and Ashforth (1992) propose that organizational identification is a specific form of social identification, which captures the perception of belonging to a group (e.g., "I am a volunteer", "I am a woman"). By being a member of an organization, individuals "may come to identify with the organization" (Dutton et al., 1994, p. 242). Specifically, organizational identification emerges when the individual incorporates aspects of the organization in their sense of self (Dutton et al., 1994).

Organizational identification is an important outcome for organizations, leading Pratt (1998) to frame identification as "a fundamental task of organizations: Organizations must engender identification to facilitate their functioning" (p. 171). The rationale here is clear: since organizations benefit from the identification of their members, they should work towards enabling identification. The importance of identification is further supported through links to work attitudes, behaviors, and outcomes such as motivation, performance, or attrition (Mael \& Ashforth, 1995; Pratt, 1998).

Organizational identification has received some attention in the volunteer context. For instance, Traeger and colleagues (2021) examine the socialization stages that volunteers proceed through to become insiders and propose organizational identification to be an outcome of this process. Boezeman \& Ellemers (2014) find volunteers show higher levels of organizational identification if leaders instill pride in the volunteers through communication about the 
effectiveness of the volunteer work and if leaders are perceived to represent the identity of the organization.

More specifically related to job crafting, research in the private sector has investigated the relationship between job crafting and organizational identification. Generally, studies find a positive correlation (Kilic et al., 2020; Wang et al., 2017), but organizational identification has both been conceptualized as an antecedent (Wang et al., 2017) and outcome (Kilic et al., 2020) of job crafting. Following the early theory on job crafting (Wrzesniewski \& Dutton, 2001), we view organizational identification as an outcome. This is further supported by more recent thinking in which Wrzesniewski and colleagues (2013) elaborate on the impact of job crafting on identity and argue "job crafting affords employees with numerous ways to infuse the self with positive meaning through connecting themselves with sources of positive regards for the organization” (p. 293). Empirical research supports this directionality. In a recent study conducted in Turkey, Kilic and colleagues (2020) find that behavioral and cognitive crafting are both positively related to organizational identification. We, therefore, hypothesize:

Hypothesis 1a: Behavioral job crafting is positively related to organizational identification.

Hypothesis 1b: Cognitive job crafting is positively related to organizational identification.

\section{Job Crafting and Volunteer Satisfaction}

Volunteer satisfaction, similar to job satisfaction (Brayfield \& Rothe, 1951), captures the individual's overall evaluation of their volunteer job. Volunteer satisfaction is an important 
construct, as it is related to volunteers' intention to stay (Ferreira et al., 2015) and the duration of their service (Omoto \& Snyder, 1995). Satisfaction is also a frequently studied outcome of job crafting (Rudolph et al., 2017; Zhang \& Parker, 2019). Given the multiple conceptualizations of job crafting over time (Tims et al., 2012, Wrzesniewski \& Dutton, 2001; Zhang \& Parker, 2019), however, not much is known about the specific relationship between behavioral and cognitive job crafting and satisfaction. However, recent evidence suggests that they are differently related to satisfaction.

With regards to behavioral crafting, Walk \& Handy (2018) found teachers who engaged in behavioral crafting showed higher levels of job satisfaction. Similarly, Leana and colleagues (2009) find collaborative crafting — crafting that requires interaction with others - is positively related to job satisfaction among childcare workers. There is also evidence suggesting cognitive crafting is related to job satisfaction. Generally, this relationship is positive in bivariate analysis (Kim et al., 2018; Slemp \& Vella-Brodrick, 2013; Walk \& Handy, 2018). In multivariate analysis, however, Walk and Handy (2018) find a negative relationship between cognitive crafting and satisfaction. The authors reason cognitive crafting "might be more demanding for individuals" (p. 364) and, thus, does not necessarily result in positive outcomes. Similarly, Leana and colleagues (2009) find a negative relationship between individual crafting — crafting done by oneself — and job satisfaction. Building on those findings, we hypothesize:

Hypothesis 2a: Behavioral crafting is positively related to volunteer satisfaction. Hypothesis 2b: Cognitive crafting is negatively related to volunteer satisfaction. 


\section{Methods}

Data were collected from volunteers in a large youth-serving nonprofit organization located in the Midwest United States. Whereas historically the organization focused on youth programming for male-identifying youth, it now offers programming to all youth. The organization relies heavily on volunteers for the provision of its programming. The volunteers can be considered long-term volunteers who are responsible for carrying out the weekly programming, as opposed to episodic volunteers, who provide short or infrequent help to a given organization (Macduff, 2005). Recruitment of volunteers was facilitated through the organization's local office. The invitation to participate in the online survey (implemented via Qualtrics) was sent to all 7,036 volunteers and reached 4,943 volunteers. The remainder were bounce-backs, mostly due to email addresses no longer being active indicating the invitation to the survey did not reach these volunteers. Of the 4,943 individuals who received the invitation, 678 took the survey, resulting in a $13.7 \%$ response rate.

\section{Variables}

\section{Dependent Variables:}

Volunteer satisfaction was measured using 3 items (e.g., "I feel fairly satisfied with my present volunteer job") taken from Brayfield \& Rothe (1951), which we adapted to the volunteer context. Coefficient alpha was high $(\alpha=.90)$. Response categories ranged from $1=$ strongly disagree to $7=$ strongly agree.

Organizational identification was measured using 6 items (Mael \& Ashforth, 1992). An example item is "When someone praises [the organization], it feels like a personal compliment" $(\alpha=.82)$. Response categories ranged from $1=$ strongly disagree to $5=$ strongly agree. 


\section{Independent Variables:}

Job crafting was measured utilizing an instrument capturing behavioral and cognitive crafting (Walk \& Handy, 2018). As job crafting has not yet been assessed on volunteers, we adapted the language to fit the volunteer context. Behavioral crafting consists of 5 items (e.g., "I have changed the way I work with others in order to more effectively achieve my volunteer goals", $\alpha=.84)$. Cognitive crafting consists of 5 items (e.g., "I have tried to redefine the scope of my volunteer responsibilities at [organization]”, $\alpha=.93)$. Response categories ranged from $1=$ strongly disagree to $7=$ strongly agree.

\section{Control Variables}

We include age (in years), tenure, and weekly volunteer hours as control variables given previously established relationships to job crafting (Rudolph et al., 2017). Since those variables are also related to volunteer satisfaction (Cnaan \& Cascio, 1998) and organizational identification (Mael \& Ashforth, 1992), we include the same control variables in all equations (Acock, 2013). Age is measured in years. Tenure is measured by asking volunteers how long they have been in their current role (in years). Weekly Volunteer Hours were assessed by asking "How many hours do you volunteer per week"? with response categories $1=<1$ hour, $2=1-2$ hours, $3=>2-3$ hours, $4=>3-5$ hours, $5=>5-10$ hours, $6=>10$ hours. Since the response categories reflect smaller increments when asking about low time commitment and larger increment categories when asking about 5 and more hours, we recoded this variable to reflect a binary variable 'high weekly hours' $(1=$ more than 5 hours, $0=5$ hours and less). Finally, we control for volunteer gender $(1=$ female, $0=$ male $)$, since previous research on the same population has identified men and women have different volunteer outcomes (Walk et al., 2018). 


\section{Data Analysis}

We use structural equation modeling to analyze our data. Before we ran a structural model to test our hypotheses, we ran a measurement model to confirm the fit of the data to our theoretical model and to confirm the discriminant validity of the scales (Podsakoff et al., 2003). We further supplemented our analysis with sequential $\chi^{2}$-difference tests comparing the full measurement model to four alternative models. The initial measurement model based on a fourfactor model indicates a good fit $(\mathrm{CFI}=.932$, TLI=.921, RMSEA=.072, SRMR=.057). Upon closer inspection, we noticed one identification item had a low multiple $\mathrm{R}^{2}(=.12)$, which we deleted from the identification factor (Hooper et al., 2008). Findings of the updated four-factor model indicate a good fit to the data $(\mathrm{CFI}=.936, \mathrm{TLI}=.925, \mathrm{RMSEA}=.074, \mathrm{SRMR}=.054)$, which is superior to a one-factor model $(\mathrm{CFI}=.501, \mathrm{TLI}=.438, \mathrm{RMSEA}=.202, \mathrm{SRMR}=.189)$ and other alternative models (see Table 1).

\section{[TABLE 1 HERE]}

\section{Findings}

We present descriptive statistics in table 2. Volunteers in the sample had a mean age of 50 years ranging from 19 to 86 years and $30 \%$ were female. This sample is comparable to the population of volunteers at the organization using administrative records with regards to age (M=45, range: $18-106)$ and gender (29.5\% female, Walk et al., 2018). Almost 17\% of the sample indicated to volunteer more than 5 hours weekly. Volunteers reported an average of 5 years for in-role tenure ranging from 0 to 17 years. Behavioral crafting was higher $(\mathrm{M}=4.52, \mathrm{SD}=1.24)$ than cognitive crafting $(\mathrm{M}=3.98, \mathrm{SD}=1.51)$. Generally, volunteers had high levels of satisfaction $(\mathrm{M}=5.70, \mathrm{SD}=1.15)$ and organizational identification $(\mathrm{M}=3.74, \mathrm{SD}=.74)$. 


\section{[TABLE 2 HERE]}

A few correlations are of note (see table 3). As expected, cognitive and behavioral crafting are highly positively correlated $(\mathrm{r}=.63, \mathrm{p}<.0001)$. Cognitive and behavioral crafting are both positively related to organizational identification $\left(\mathrm{r}_{\mathrm{cog}}=.17, \mathrm{p}<.0001 ; \mathrm{r}_{\mathrm{beh}}=.30, \mathrm{p}<.0001\right)$, but only behavioral crafting is correlated with satisfaction ( $\left.\mathrm{r}_{\mathrm{beh}}=.17, \mathrm{p}<.0001\right)$. Although some of the variables had substantial correlations, the variance inflation factor is low (VIF<1.76).

\section{[TABLE 3 \& FIGURE 1 HERE]}

We present an overview of our findings in figure 1. Table 3 contains full path model results alongside control variables ${ }^{2}$. It is of note that volunteers who volunteer more than 5 hours weekly show higher levels of behavioral crafting $(\beta=.22, p<.0001)$ and cognitive crafting $(\beta=.11$, $\mathrm{p}=.013$ ). Moreover, volunteers who have higher in-role tenure are less likely to engage in behavioral crafting ( $\beta=-.09, p=.033)$. We support hypothesis $1 \mathrm{a}$; behavioral crafting is related to organizational identification $(\beta=.33, \mathrm{p}<.0001)$. Although we had initially hypothesized in hypothesis $1 \mathrm{~b}$ that cognitive job crafting would be positively related to organizational identification, this hypothesis was not supported by our findings $(\beta=-.06, p=.24)$. The findings also indicate behavioral and cognitive crafting are related to satisfaction in the expected directions. Specifically, we support hypothesis 2a indicating a positive relationship between

\footnotetext{
${ }^{2}$ Given the wide-ranging age of the volunteers, we ran the same set of models on several subsamples, excluding observations at the top and the bottom 1 and $5 \%$ in terms of age values. We did not find qualitative differences between those models and the reported model (analyses upon request).
} 
behavioral crafting and satisfaction $(\beta=.32, \mathrm{p}<.0001)$ while cognitive crafting is negatively related to satisfaction ( $\beta=.-25, \mathrm{p}<.0001)$, supporting hypothesis $2 \mathrm{~b}$.

[TABLE 3 ABOUT HERE]

\section{Discussion}

This study focuses on volunteers as active participants and shapers of their volunteer experience. As proposed in the literature review and tested with survey data, this study shows volunteers utilize job crafting to enact changes in the context of their volunteer work. Our findings suggest job crafting, as a self-initiated, bottom-up approach towards job design in which individuals alter their work or how they see their work by making physical and/or cognitive changes, as particularly meaningful in the volunteer context as it allows volunteers to align the volunteer environment with their needs. We proposed satisfaction and organizational identification as vital outcomes of job crafting in the volunteer context and, generally, find this to be the case. This study, therefore, contributes to an extended understanding of job crafting in the non-work context (De Bloom et al., 2020).

Specifically, findings show behavioral crafting is positively related to organizational identification while cognitive crafting is not. We can only speculate about the reasons at this point since research has only recently started to investigate the relationship between job crafting forms and organizational identification (Kilic et al., 2020). It may be the nature of behavioral crafting, which requires a tangible interaction with the work environment, that lies at the heart of this finding. Pratt (1998) suggests a link between behaviors and organizational identification. Individuals strive for consistency in their behaviors. This tendency is especially vital in the case of behaviors that are public and can be observed by others. These behaviors, in turn, bind the individual to the organization in which these behaviors occur and, thus, are likely to induce 
organizational identification (Pratt, 1998). Such a link has not been established for intangible aspects such as cognition. This reasoning may explain and provide some context to our findings. It may also be that volunteers craft differently from paid employees, who were studied previously (Kilic et al., 2020). Future research is needed to further examine these relationships. Confirming our hypotheses, behavioral crafting has a positive relationship to satisfaction whereas cognitive crafting has a negative relationship. Generally, these findings replicate earlier work among teachers (Walk \& Handy, 2018) and childcare workers (Leana et al., 2009). Since cognitive crafting is done 'in one's head', it can be more straining and may therefore not result in increased satisfaction. Behavioral crafting, as it addresses the structural aspects of the environment, may lead to visible changes in the volunteer work. Further, whereas behavioral and cognitive crafting are related, they may have different properties. For instance, Burning and Campion (2018) suggested cognitive crafting could be conceptualized as a process. As such, an individual may participate in the same form of cognitive crafting every single day in comparison to a (potentially) one-time behavioral crafting action. If volunteers have to continuously engage in cognitive crafting, one would expect them to be fatigued and, thus, not particularly satisfied. Generally, our findings support the notion that behavioral and cognitive crafting may have different sets of outcomes (Niessen et al., 2016; Slemp \& Vella-Brodrick, 2013). Even though more research is needed to better understand the complexity of those relationships, especially in the understudied volunteer context, the present study hints at the importance of a multifaceted conceptualization of job crafting in the non-work context (De Bloom et al., 2020).

Both our descriptive and multivariate analyses provide insights into which volunteers are likely to craft their volunteer jobs. Across those types of analyses, we find volunteers who volunteer more than 5 hours weekly show more tendencies to engage in either job crafting form. 
Past research finds volunteers who spend a significant amount of their time volunteering have distinct qualities. For instance, Einolf and Yung (2018) suggest those volunteers may have stronger motives compared to volunteers who commit fewer hours. As such, it may be that those dedicated volunteers have a high commitment to their volunteer work and aim to 'make it work' because of their commitment to the cause. Future research should, therefore, investigate the relationship between volunteer motives and volunteer job crafting. Moreover, our multivariate analysis indicates volunteers who have been in their role longer are less likely to engage in behavioral crafting. We reason that volunteers may perceive the need to make changes in their volunteer role early on, but the need to behaviorally craft their volunteer work may decrease over time. Therefore, we encourage future research to capture volunteer crafting behavior over time.

Generally, the experience volunteers have while volunteering matters (Wilson, 2012). Following others (Erks et al., 2020; Traeger \& Alfes, 2019; do Nascimento et al., 2018), the present study took on a volunteer-centered perspective by focusing on job crafting as selfdirected, bottom-up behavior and findings indicate that volunteers, indeed, are active shapers of their work. We hope that researchers will incorporate this perspective as a factor in future volunteer management research.

\section{Practical Implications}

Aside from contributions to theory and research, this study has implications for managerial practice. Like other organizations, nonprofits depend on the organizational identification of their members for their functioning (Boezeman \& Ellemers, 2014; Pratt, 1998). Based on the relationship between job crafting and identification, there is some good news for those managing volunteers as they can create a supportive environment for job crafting. For instance, facilitation of job crafting could happen by signaling to volunteers it is acceptable to 
make changes to their volunteer roles. Further, volunteer managers can also engage in dialogue with their volunteers to distill if there are aspects of their roles that they would like to see changed. Further, given the finding that those who commit more hours to their volunteer work are more likely to engage in job crafting, volunteer managers can focus on this group first and extend support (e.g., through targeted communication).

\section{Limitations}

This study is not without limitations. The cross-sectional nature of the data does not allow us to draw causal conclusions. Whereas we grounded our hypotheses in previous theory and literature, we cannot eliminate the risk of reverse causality. For instance, organizational identification in our model was an outcome, but could also be conceptualized as antecedent and, therefore, lead to more job crafting (Wang et al., 2017). Along the same lines, research in the volunteer context finds volunteering more hours leads to organizational identification and subsequently is positively related to an increase in volunteer hours (Grube \& Piliavin, 2000). To minimize concerns of common-methods bias, we took an a priori approach during survey development (Podsakoff et al., 2003). For instance, the survey instrument mitigated item characteristic and item context effects by using different scale anchors and different scale formats and by dispersing measures related to this study throughout the survey and asking participants to respond to unrelated measures (i.e., perceptions of training) in between. Still, we encourage future researchers to design and implement longitudinal studies to tease out those effects and establish causality. Moreover, whereas there are many similar organizations in structure and size to the one we study, we cannot draw conclusions beyond the specific volunteer context of a youth-serving nonprofit in one specific location. We would therefore welcome 
replication studies in different volunteer contexts and across geographical locations. Replication in other contexts would also help alleviate concerns around the low response rate.

\section{Future Research}

As the research on job crafting in the volunteer context is just emerging, we recommend future research to explore potential antecedents and volunteer outcomes. With regards to individual-level antecedents, we especially suggest studying volunteer motivation to elicit which motives are related to volunteer crafting efforts. Organizational-level antecedents that may be valuable in the volunteer context are autonomy and opportunity to job craft in the specific context (Wrzesniewski \& Dutton, 2001), especially since volunteer work tends to be characterized as autonomous (Englert et al., 2020). This may be studied through observation of larger organizations which engage volunteers, with multiple branches that follow different management models to better understand the relationship between organizational-level antecedents and job crafting. Further, we suggest studying the impact of effective volunteer management to enable job crafting. Following recent research in the paid employee context, we see the value in studying human resource practices (Meijerink et al., 2018) or leadership behaviors (Wang et al., 2017) and their impact on job crafting. With regards to outcomes, and as briefly indicated in the literature review, job crafting has been linked to the meaning of work (Bruning \& Campion, 2018), psychological well-being (Berg et al., 2010b), and performance (Bruning \& Campion, 2018; Leana et al., 2009). We would like to see studies incorporating those constructs to test whether and to what extent these are meaningful in the volunteer context and to what degree these forms of job crafting are related to volunteer turnover and retention. We also encourage future research to investigate potential negative outcomes, such as fatigue or burnout, especially with regards to cognitive crafting (Berg et al., 2013; Walk \& Handy, 2018). 
Related to the multifaceted nature of job crafting it is important to further clarify how behavioral and cognitive crafting are related (Melo et al., 2021; Hu et al., 2020; Romeo, et al., 2020). Since not much is known about the multifaceted nature of job crafting in the non-work context (De Bloom et al., 2020), we recommend future research to further examine the multidimensional nature of job crafting with a specific focus on the nature of the relationship between the individual crafting forms. As we are cognizant of the limitations of survey research, we also encourage future research to engage in qualitative work to capture how volunteers view job crafting opportunities and how they craft their volunteer work.

\section{Conclusion}

While considerable prior research on job crafting has focused on the paid employee context (De Bloom et al., 2020), our findings deepen our understanding of job crafting in the non-work context and further support the claim that studying proactive behavior among volunteers matters (do Nascimento et al., 2018). Our findings support that volunteers, rather than being passive recipients, are actively shaping their volunteer experience. More specifically, we find volunteers craft their work to change volunteer satisfaction and, in some cases, organizational identification. Understanding job crafting as it relates to volunteer work leads to a better understanding of overall commitment to a volunteer role. This inquiry is especially vital since volunteers have lower barriers to exit; understanding how they value their work and view themselves within a role can help to increase individual outcomes, as shown here, and eventually also impact organizational outcomes, such as retention. 


\section{References}

Acock, A.C. (2013). Discovering structural equation modeling using Stata. Stata Press Books.

Akingbola, K., Rogers, S.E., \& Baluch, A. (2019). Change management in nonprofit organizations: Theory and practice. Springer.

Berg, J., Dutton, J. E., \& Wrzesniewski, A. (2013). Job crafting and meaningful work. In B. J. Dik, Z. S. Byrne, \& M. F. Steger (Eds.), Purpose and meaning in the workplace. (pp. 81104). American Psychological Association.

Berg, J., Grant, A., \& Johnson, V. (2010a). When callings are calling: Crafting work and leisure in pursuit of unanswered occupational callings. Organization Science, 21(5), 973-994.

Berg, J., Wrzesniewski, A., \& Dutton, J.E. (2010b). Perceiving and responding to challenges in job crafting at different ranks: When proactivity requires adaptivity. Journal of Organizational Behavior, 31(2-3), 158-186.

Boezeman, E.J., \& Ellemers, N. (2014). Volunteer leadership: The role of pride and respect in organizational identification and leadership satisfaction. Leadership, 10(2), 160-173.

Brayfield, A. H., \& Rothe, H. F. (1951). An index of job satisfaction. Journal of Applied Psychology, 35(5), 307-311.

Bruning, P.F., \& Campion, M.A. (2018). A Role-resource Approach-avoidance Model of Job Crafting: A Multimethod Integration and Extension of Job Crafting Theory. Academy of Management Journal, 61(2), 499-522.

De Bloom, J., Vaziri, H., Tay, L., \& Kujanpää, M. (2020). An identity-based integrative needs model of crafting: Crafting within and across life domains. Journal of Applied Psychology, 105(12), 1423. 
Dierdorff, E.C., \& Jensen, J.M. (2018). Crafting in context: Exploring when job crafting is dysfunctional for performance effectiveness. Journal of Applied Psychology, 103(5), 463477.

do Nascimento, T.T., Porto, J.B., \& Kwantes, C.T. (2018). Transformational leadership and follower proactivity in a volunteer workforce. Nonprofit Management and Leadership, 28(4), 565-576.

Dutton, J.E., Dukerich, J.M., \& Harquail, C.V. (1994). Organizational images and member identification. Administrative Science Quarterly, 239-263.

Dutton, J.E., \& Wrzesniewski, A. (2020, March 12). What Job Crafting Looks Like. Harvard Business Review. Retrieved from https://hbr.org/2020/03/what-job-crafting-looks-like

Einolf, C. (2018). Evidence-based volunteer management: A review of the literature. Voluntary Sector Review, 9(2), 153-176.

Einolf, C., \& Yung, C. (2018). Super-volunteers: Who are they and how do we get one? Nonprofit and Voluntary Sector Quarterly, 47(4), 789-812.

Englert, B., Thaler, J., \& Helmig, B. (2020). Fit Themes in Volunteering: How Do Volunteers Perceive Person-Environment Fit? Nonprofit and Voluntary Sector Quarterly, 49(2), $336-356$.

Erks, R.L., Allen, J.A., Harland, L.K., \& Prange, K. (2020). Do Volunteers Volunteer to Do More at Work? The Relationship Between Volunteering, Engagement, and OCBs. VOLUNTAS. https://doi.org/10.1007/s11266-020-00232-7

Ferreira, M.R., Proença, T., \& Proença, J.F. (2015). Volunteering for a lifetime? Volunteers' intention to stay in Portuguese Hospitals. VOLUNTAS, 26(3), 890-912.

Fuller, A., \& Unwin, L. (2017). Job Crafting and Identity in Low-Grade Work: How Hospital 
Porters Redefine the Value of their Work and Expertise. Vocations and Learning, 10(3), 307-324.

Gecas, V. (1982). The Self-Concept. Annual Review of Sociology, 8(1), 1-33.

Geldenhuys, M., Bakker, A.B., \& Demerouti, E. (2020). How task, relational and cognitive crafting relate to job performance: A weekly diary study on the role of meaningfulness. European Journal of Work and Organizational Psychology, 1-12.

Grant, A.M., \& Ashford, S.J. (2008). The dynamics of proactivity at work. Research in Organizational Behavior, 28, 3-34.

Grube, J.A., \& Piliavin, J. A. (2000). Role identity, organizational experiences, and volunteer performance. Personality and Social Psychology Bulletin, 26(9), 1108-1119.

Hackman, J.R., \& Oldham, G.R. (1976). Motivation through the design of work: Test of a theory. Organizational Behavior and Human Performance, 16(2), 250-279.

Haivas, S., Hofmans, J., \& Pepermans, R. (2013). Volunteer engagement and intention to quit from a self-determination theory perspective. Journal of Applied Social Psychology, 43(9), 1869-1880.

Hager, M., \& Brudney, J. (2008). Management Capacity and Retention of Volunteers. In M. Liao-Troth (Ed.), Challenges in Volunteer Management (pp. 9-27). Information Age Publishing.

Henderson, A.C., \& Sowa, J.E. (2018). Retaining Critical Human Capital: Volunteer Firefighters in the Commonwealth of Pennsylvania. VOLUNTAS, 29, 43-58.

Hooper, D., Coughlan, J., \& Mullen, M. (2008). Structural equation modelling: Guidelines for determining model fit. Electronic Journal of Business Research Methods, 6(1), 53-60. 
Hu, Q., Taris, T.W., Dollard, M.F., \& Schaufeli, W.B. (2020). An exploration of the component validity of job crafting. European Journal of Work and Organizational Psychology, 29(5), 776-793.

Kilic, E., Tatar, B., \& Erdil, O. (2020). The Relationship Between Job Crafting and Organizational Identification: The Mediating Role of Affective Well-being. Business and Economics Research Journal, 11(1), 201-212.

Kim, H., Im, J., Qu, H., \& NamKoong, J. (2018). Antecedent and consequences of job crafting: An organizational level approach. International Journal of Contemporary Hospitality Management, 30(3), 1863-1881.

Leana, C., Appelbaum, E., \& Shevchuk, I. (2009). Work process and quality of care in early childhood education: The role of job crafting. Academy of Management Journal, 52(6), 1169-1192.

Lin, B., Law, K. S., \& Zhou, J. (2017). Why is underemployment related to creativity and OCB? A task-crafting explanation of the curvilinear moderated relations. Academy of Management Journal, 60(1), 156-177.

Macduff, N. (2005). Societal Changes and the Rise of the Episodic Volunteer. 1, 49-61.

Mael, F.A., \& Ashforth, B.E. (1992). Alumni and their alma mater: A partial test of the reformulated model of organizational identification. Journal of Organizational Behavior, $13(2), 103-123$.

Mael, F.A., \& Ashforth, B.E. (1995). Loyal from day one: Biodata, organizational identification, and turnover among newcomers. Personnel Psychology, 48(2), 309-333.

Meijerink, J., Bos-Nehles, A., \& Leede, J. de. (2018). How employees’ pro-activity translates high-commitment HRM systems into work engagement: The mediating role of job 
crafting. The International Journal of Human Resource Management, 31(22), 28932918.

Melo, N., Dourado, D., \& Andrade, J. (2021). Reclaiming cognitive crafting: An integrative model of behavioral and cognitive practices in job crafting. International Journal of Organizational Analysis. https://doi.org/10.1108/IJOA-04-2020-2130

Niessen, C., Weseler, D., \& Kostova, P. (2016). When and why do individuals craft their jobs? The role of individual motivation and work characteristics for job crafting. Human Relations, 69(6), 1287-1313.

Omoto, A.M., \& Snyder, M. (1995). Sustained helping without obligation: Motivation, longevity of service, and perceived attitude change among AIDS volunteers. Journal of Personality and Social Psychology, 68(4), 671.

Podsakoff, P.M., MacKenzie, S.B., Lee, J.-Y., \& Podsakoff, N.P. (2003). Common method biases in behavioral research: A critical review of the literature and recommended remedies. Journal of Applied Psychology, 88(5), 879-903.

Pratt, M.G. (1998). To Be or Not to Be? Central questions in organizational identification. In D.
A. Whetten \& P. C. Godfrey, Identity in organizations. Building Theory Through Conversations (Vol. 24, pp. 171-207). SAGE.

Rosso, B.D., Dekas, K.H., \& Wrzesniewski, A. (2010). On the meaning of work: A theoretical integration and review. Research in Organizational Behavior, 30, 91-127.

Rudolph, C.W., Katz, I.M., Lavigne, K.N., \& Zacher, H. (2017). Job crafting: A meta-analysis of relationships with individual differences, job characteristics, and work outcomes. Journal of Vocational Behavior, 102, 112-138.

Slemp, G.R., \& Vella-Brodrick, D.A. (2013). The Job Crafting Questionnaire: A new scale to 
measure the extent to which employees engage in job crafting. International Journal of Wellbeing, 3(2), 126-146.

Spreitzer, G.M. (1995). Psychological empowerment in the workplace: Dimensions, measurement, and validation. Academy of Management Journal, 38(5), 1442-1465.

Studer, S., \& von Schnurbein, G. (2013). Organizational factors affecting volunteers: A literature review on volunteer coordination. VOLUNTAS, 24(2), 403-440.

Sturges, J. (2008). All in a day's work? Career self-management and the management of the boundary between work and non-work. Human Resource Management Journal, 18(2), $118-134$.

Tajfel, H., \& Turner, J.C. (1979). An integrative theory of intergroup conflict. In W. G. Austin \& S. Worchel (Eds.), The social psychology of intergroup relations (pp. 33-47). BrooksCole.

Tims, M., Bakker, A.B., \& Derks, D. (2012). Development and validation of the job crafting scale. Journal of Vocational Behavior, 80(1), 173-186.

Traeger, C., \& Alfes, K. (2019). High-Performance Human Resource Practices and Volunteer Engagement: The Role of Empowerment and Organizational Identification. VOLUNTAS, 30(5), 1022-1035.

Traeger, C., Haski-Leventhal, D., \& Alfes, K. (2021). Extending organizational socialization theory: Empirical evidence from volunteer work for refugees in France and Australia. Human Relations.

Walk, M., \& Handy, F. (2018). Job Crafting as Reaction to Organizational Change. The Journal of Applied Behavioral Science, 54(3), 349-370.

Walk, M., Zhang, R., \& Littlepage, L. (2019). “Don’t you want to stay?” The impact of training 
and recognition as human resource practices on volunteer turnover. Nonprofit Management and Leadership, 29(4), 509-527.

Wang, H.-J., Demerouti, E., \& Le Blanc, P. (2017). Transformational leadership, adaptability, and job crafting: The moderating role of organizational identification. Journal of Vocational Behavior, 100, 185-195.

Willems, J., \& Walk, M. (2013). Assigning volunteer tasks: The Relation between task preferences and functional motives of youth volunteers. Children and Youth Services Review, 35(6), 1030-1040.

Wilson, J. (2012). Volunteerism Research: A Review Essay. Nonprofit and Voluntary Sector Quarterly, 41(2), 176-212.

Wrzesniewski, A., \& Dutton, J.E. (2001). Crafting a Job: Revisioning Employees as Active Crafters of Their Work. The Academy of Management Review, 26(2), 179-201.

Wrzesniewski, A., LoBuglio, N., Dutton, J.E., \& Berg, J.M. (2013). Job Crafting and Cultivating Positive Meaning and Identity in Work. In A. B. Bakker (Ed.), Advances in Positive Organizational Psychology (Vol. 1, pp. 281-302). Emerald Group Publishing Limited.

Zhang, F., \& Parker, S.K. (2019). Reorienting job crafting research: A hierarchical structure of job crafting concepts and integrative review. Journal of Organizational Behavior, 40(2), $126-146$. 
Figure 1 SEM Path Model Results

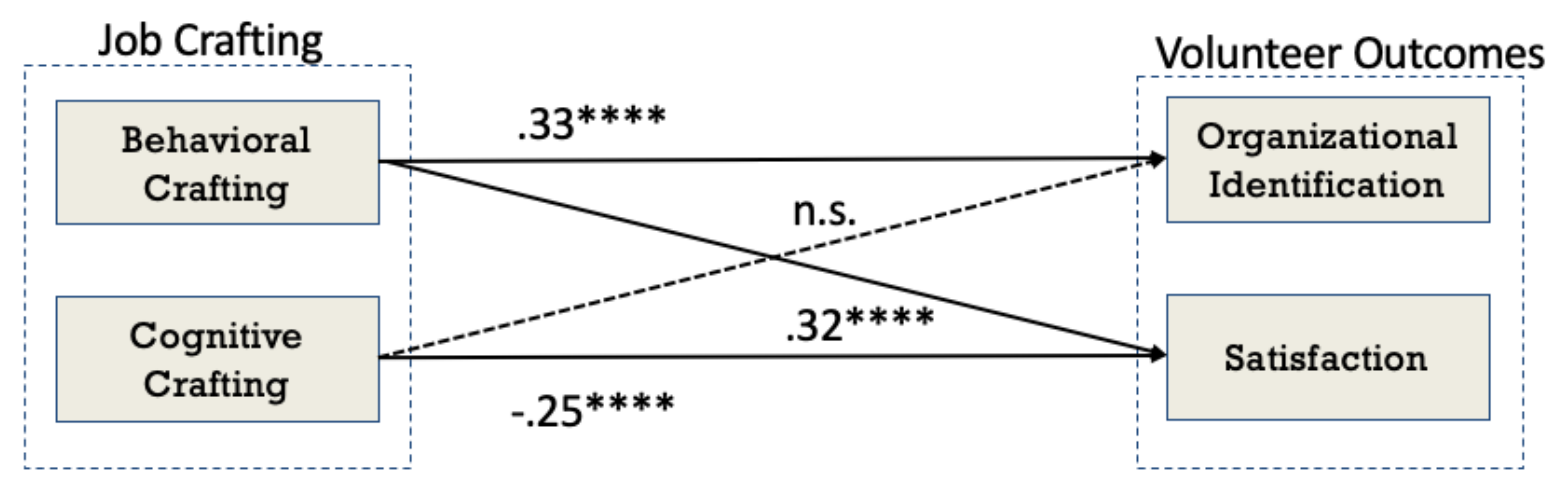

Note: $* \mathrm{p}<.05, * * \mathrm{p}<.01, * * * \mathrm{p}<.001, * * * * \mathrm{p}<.0001$. Controls (included but not displayed): age, gender weekly, volunteer hours, in-role tenure. 
Table 1 Measurement Model Comparison

\begin{tabular}{lllllllll} 
Models & $\chi^{2}$ (df) & TLI & CFI & RMSEA & SRMR & $\chi^{2}$ diff & df diff \\
\hline $\begin{array}{l}\text { Full } \\
\text { Measurement }\end{array}$ & & & & & & & & \\
Model & $513(129)$ & 0.925 & 0.936 & $.074[.067, .081]$ & 0.054 & $/$ & $/$ \\
Model A & $965(132)$ & 0.840 & 0.862 & $.108[.101, .114]$ & 0.087 & 452 & $3^{* * * * *}$ \\
Model B & $1491(132)$ & 0.739 & 0.775 & $.137[.131, .144]$ & 0.134 & 978 & $3^{* * * *}$ \\
Model C & $3134(135)$ & 0.438 & 0.504 & $.202[.196, .208]$ & 0.189 & 2621 & $6^{* * * *}$ \\
\hline
\end{tabular}

$\mathrm{N}=545, * * * * \mathrm{p}<.0001$, Models run using listwise deletion.

$\chi 2$ Chi-square; df degrees of freedom; TLI Tucker-Lewis index; CFI comparative fit index; RMSEA root mean square error of approximation; SRMR standardized root mean square residual; $\chi^{2}$ diff difference in Chi-square; df diff difference in degrees of freedom. All models are compared to the full measurement model.

Model A: behavioral and cognitive crafting into one factor; Model B: satisfaction and organizational identification as one factor; Model C: all factors into one single factor. 
Table 2 Descriptive Statistics

\begin{tabular}{|c|c|c|c|c|c|}
\hline Variable & $\mathbf{N}$ & Mean & Std.Dev. & Min & Max \\
\hline $\begin{array}{l}\text { Volunteer Hours ( } 1=5 \text { hrs or } \\
\text { more) }\end{array}$ & 607 & .166 & .373 & 0 & 1 \\
\hline In-Role Tenure (yrs) & 606 & 5.152 & 4.953 & 0 & 17 \\
\hline Female & 634 & .295 & .456 & 0 & 1 \\
\hline Age & 600 & 50.57 & 12.61 & 19 & 86 \\
\hline Cognitive Crafting & 558 & 3.978 & 1.505 & 1 & 7 \\
\hline Behavioral Crafting & 554 & 4.524 & 1.239 & 1 & 7 \\
\hline Satisfaction & 576 & 5.703 & 1.152 & 1 & 7 \\
\hline Organizational Identification & 567 & 3.736 & .737 & 1 & 5 \\
\hline
\end{tabular}


Table 3 Correlations

\begin{tabular}{|c|c|c|c|c|c|c|c|c|}
\hline & 1 & 2 & 3 & 4 & 5 & 6 & 7 & 9 \\
\hline 1. Vol. Hours & 1 & & & & & & & \\
\hline 2. Tenure & $0.094^{*}$ & 1 & & & & & & \\
\hline 3. Female & $-0.079+$ & $-0.107^{* *}$ & 1 & & & & & \\
\hline 4. Age & $0.078+$ & $0.416^{* * * *}$ & $-0.155^{* * * *}$ & 1 & & & & \\
\hline $\begin{array}{l}\text { 5. Behavioral } \\
\text { Crafting }\end{array}$ & $0.224^{* * * *}$ & $-0.071+$ & -0.070 & -0.027 & 1 & & & \\
\hline $\begin{array}{l}\text { 6. Cognitive } \\
\text { Crafting }\end{array}$ & $0.128^{* *}$ & -0.022 & $-0.074+$ & 0.006 & $0.625^{* * * *}$ & 1 & & \\
\hline 7. Satisfaction & 0.067 & $-0.109^{* *}$ & 0.050 & $-0.079+$ & $0.174^{* * * *}$ & -0.065 & 1 & \\
\hline 8. Identification & $0.153^{* * * *}$ & 0.052 & -0.045 & $0.154^{* * * *}$ & $0.301^{* * * *}$ & $0.195^{* * * *}$ & $0.283^{* * * *}$ & 1 \\
\hline
\end{tabular}

Note: $+\mathrm{p}<.10, * \mathrm{p}<.05, * * \mathrm{p}<.01, * * * \mathrm{p}<.001, * * * * \mathrm{p}<.0001$; rounded to three decimals. 
Table 4 SEM Path Analysis Results predicting Satisfaction and Organizational Identification

\begin{tabular}{lcccc} 
& $\begin{array}{c}\text { Cognitive Job } \\
\text { Crafting }\end{array}$ & $\begin{array}{c}\text { Behavioral Job } \\
\text { Crafting }\end{array}$ & Satisfaction & $\begin{array}{c}\text { Organizational } \\
\text { Identification }\end{array}$ \\
\hline Weekly Hrs & $.11^{*}[.02, .19]$ & $.22^{* * * *}[.14, .30]$ & $.03[-.06, .11]$ & $.07[-.01, .15]$ \\
Tenure & $-.04[-.13, .05]$ & $-.10^{*}[-.19,-.01]$ & $-.06[-.15, .04]$ & $-.01[-.08, .10]$ \\
Female & $-.07[-.16, .01]$ & $-.06[-.14, .03]$ & $.03[-.05, .12]$ & $-.01[-.10, .07]$ \\
Age & $.01[-.10, .09]$ & $-.01[-.10, .09]$ & $-.01[-.10, .08]$ & $.19^{* * * *}[.10, .28]$ \\
Cognitive Job & - & - & $-.25^{* * * *}[-.36,-$ & $-.06[-.16, .04]$ \\
Crafting \\
Behavioral Job \\
Crafting
\end{tabular}

Note: $\mathrm{N}=525$; coefficients rounded to two decimals; confidence intervals in brackets; ${ }^{*} \mathrm{p} \leq .05,{ }^{* *} \mathrm{p} \leq .01$, $* * * \mathrm{p} \leq .001, * * * * \mathrm{p} \leq .0001$. Models run using listwise deletion. Error terms for crafting forms allowed to correlate. 